\title{
Photoreceptors and CSF-Contacting Neurons in the Pineal Organ of a Teleost Fish Have Direct Axonal Connections with the Brain: An HRP-Electron-Microscopic Study
}

\author{
Peter Ekström \\ Department of Zoology, University of Lund, Lund, Sweden, and Department of Anatomy and Cytobiology, University of \\ Giessen, Giessen, Federal Republic of Germany
}

\begin{abstract}
Neural signals transmitted from the pineal organ to the brain in cold-blooded vertebrates provide information about ambient illumination, information of importance for the synchronization of activity rhythms with the light-dark cycle. The ultrastructure of intrapineal projection neurons (pineal "ganglion cells") was studied after retrograde fllling with HRP through their cut axons. The dominating neuronal type is a small bipolar cell. It is present in largest numbers in the pineal stalk. This cell type displays several morphological features characteristic of cerebrospinal fluid (CSF)-contacting neurons. An apical dendritelike process extends toward the central lumen of the pineal organ. This dendritic process contains numerous mitochondria, it may have several fine branches, and it may possess a ciliumlike structure. An axon emerges from the basal pole of the neuron and joins the pineal tract. This CSF-contacting neuron is postsynaptic to photoreceptor basal pedicles with ribbontype synapses. Such synapses may occur on the neuronal soma but are mostly observed on small, basally located processes in the vicinity of the axon. There is a significant similarity between this cell type and the bipolar cells bearing a Landolt's club in the retina. In the rostral part of the pineal end-vesicle, several large photoreceptors were labeled. These photoreceptors may, consequently, have axons more than $1 \mathrm{~mm}$ long. An intriguing possibility is that this previously unknown vertebrate photoreceptor type conveys graded potentials over long distances.
\end{abstract}

The pineal organ of poikilothermic vertebrates is a photosensory structure (Meissl and Dodt, 1981). The pineal photoreceptors, which for comparative anatomical reasons have been termed conelike (Eakin and Westfall, 1961; Oksche, 1971), respond with a graded hyperpolarization to light stimulations of all wavelengths (Tabata et al., 1975; Pu and Dowling, 1981; Morita et al., 1985; Ekström and Meissl, 1986; Meissl and Ekström, 1986). The so-called ganglion cells, i.e., the intrapineal neurons that project into the brain via the pineal tract (references in Ekström, 1984; Ekström and van Veen, 1984), are spontaneously active

\footnotetext{
Received Mar. 22, 1986; revised June 25, 1986; accepted Aug. 8, 1986.

This study was supported by the Alexander von Humboldt-foundation, Bonn, F.R.G., and by the Swedish Natural Science Research Council (Grant B8554100). The support of Prof. A. Oksche and Dr. H.-W. Korf, Giessen, during the experiments is gratefully acknowledged. I would like to thank Ms. R. Wallén for her expert technical assistance, and Ms. I. Norling for photographic aid.

Correspondence should be addressed to Peter Ekström, Department of Zoology, University of Lund, Helgonavägen 3, S-223 62 Lund, Sweden.

Copyright (C) 1987 Society for Neuroscience $0270-6474 / 87 / 040987-09 \$ 02.00 / 0$
}

in the dark. Iight stimulation of all wavelengths causes inhibition followed by Off responses at stimulus offset. These are the achromatic or luminance units (Meissl and Dodt, 1981). A minor proportion of the ganglion cells, the chromatic units, are inhibited by short-wavelength exposure and are excited by subsequent medium- or long-wavelength exposure (Meissl and Dodt, 1981).

In some teleosts, the area of the skull covering the pineal organ is specialized, "the pineal window." This window seems to facilitate light penetration to the organ (Meissl and Dodt, 1981). In any case, it does not provide any means for focusing of the incident light, and, in view of the irregular organization of photoreceptors in the pineal epithelium, which is often strongly convoluted (Vollrath, 1981), it seems unlikely that anything but diffusc light reaches the pineal organ. Thus, the pineal organ may transmit information about ambient light intensity and, possibly, also about spectral composition. This information is important for the regulation of cyclic physiological parameters, which are coordinated by the daily light-dark changes. The neural signals transmitting this information to the brain are probably unobscured by signals related to contrast and movement.

In the brain, however, neural information from the pineal organ is obviously directly integrated with signals from the retina. Experimental studies of the central projections of pineal neurons have revealed axonal connections with the habenular nuclei, the periventricular hypothalamus and tegmentum, the dorsal thalamus, and the pretectal area (Ekström, 1984, 1985; Ekström and van Veen, 1984). The latter areas coincide with those receiving retinofugal innervation (Ekström, 1984).

In spite of the "simple" light responses of the pincal organ, the underlying neural circuitry has never been analyzed. The pineal organ of the rainbow trout is a favorable model to study the underlying interactions of photoreceptors and neurons. It encompasses achromatic units and a small number of chromatic units (Dodt, 1963; Morita, 1966). This is the first part of a series of investigations attempting to analyze the synaptic circuitry of a simple vertebrate photoreceptor organ, by means of ultrastructural analysis of neural elements that have been identified by their central connections (present study), and of electrophysiologically characterized single units (P. Ekström and H. Meissl, unpublished observations).

\section{Materials and Methods}

Twenty rainbow trout, Salmo gairdneri Richardson, $10-20 \mathrm{~cm}$ in length, were obtained from a local hatchery and kept as specified in an earlier 
study (Ekström and Korf, 1985). For the cxpcriments, the fishes werc decapitated and the pineal area was exposed. A crystal of HRP (Sigma, grade VI) was dissolved in the cerebrospinal fluid (CSF) surrounding the exposed pineal stalk, which was then cut with microscissors. Excess HRP was rinsed away with tissue culture medium (Dulbecco's modified Eagle Medium, DMEM; Ekström, 1985) after $1 \mathrm{~min}$. The pineal organ was excised and placed in fresh DMEM. Care was taken not to touch the pineal organ, which was lifted by the surrounding dorsal sac tissue. The excised pineal organs were incubated in DMEM overnight at $4^{\circ} \mathrm{C}$ (for details, see Ekström, 1985; Ekström and Korf, 1985).

As controls, pineal organs were excised and incubated overnight without application of HRP to the lesioned stalk ( 2 specimens) or incubated overnight in DMEM to which HRP had been added-ca. 10 crystals to 4 specimens. (One of these was mechanically injured ca. $300 \mu \mathrm{m}$ from the lesion sitc.) Further, the handling and incubation of the pincal organs at $4^{\circ} \mathrm{C}$ ensure a minimal pinocytotic uptake from the pineal lumen (references in Ekström, 1985).

After incubation, the pineal organs were fixed in $2.5 \%$ glutaraldehyde in 0.1 м Sörensen phosphate buffer ( $\mathrm{pH} \mathrm{7.2)} \mathrm{for} 1 \mathrm{hr}$, subsequently rinsed in several changes of phosphate buffer, and transferred to $0.1 \mathrm{M}$ Tris- $\mathrm{HCl}$ buffer (pH 7.2). The HRP was visualized as follows: (1) 60 min preincubation in $0.025 \% 3,3^{\prime}$-diaminobenzidine tetrahydrochloride (DAB) in $0.1 \mathrm{~m}$ Tris- $\mathrm{HCl}$ buffer ( $\mathrm{pH} \mathrm{7.2)} \mathrm{containing} 0.01 \mathrm{~m}$ imidazole (Ekström, 1985); (2) 45 min incubation in freshly made preincubation medium, containing $0.015 \%$ hydrogen peroxide; (3) 60 min incubation in fresh medium as described in (2). All incubations were performed at room temperature, in the dark. After a thorough rinse in Tris- $\mathrm{HCl}$ buffer, the specimens were transferred to $0.1 \mathrm{M}$ Sörensen phosphate buffer and postfixed in $2 \% \mathrm{OsO}_{4}$ in $0.1 \mathrm{M}$ Sörcnscn buffer for $1 \mathrm{hr}$ at $4^{\circ} \mathrm{C}$. Following a thorough rinse in phosphate buffer, the specimens were dehydrated in graded alcohol series, and transferred via propylene oxide to soft Araldite.

Serial $5 \mu \mathrm{m}$ sections of the pineal organs were mounted on precleaned glass slides, sprayed with a thin silicon film (Baysilon, Bayer) to facilitate reembedding, and stained with toluidine blue/Azure II (Ekström et al., 1983). After light-microscopical analysis, the $5 \mu \mathrm{m}$ sections were reembedded in soft Araldite. Thin to ultrathin (gray to gold) serial sections were collected on single slot or barred copper grids, poststained with uranyl acetate and lead citrate (Ekström et al., 1983), and examined in a Zeiss EM 10 electron microscope.

\section{Results}

After application of HRP to the severed pineal tract and overnight incubation of the explanted pineal organs, neural elements massively labeled with HRP-reaction product were observed in the pineal stalk and end-vesicle (for a detailed light-microscopical analysis, scc Ekström and Korf, 1985). Thc control cxperiments support the interpretation that these neural elements have been labeled by retrograde diffusion of HRP through their axons. Pineal organs that were incubated in DMEM overnight in the absence of HRP never contained any labeled elements, ruling out the possibility of the presence of cells with a high endogenous peroxidase activity. Pineal organs that were incubated in the presence of HRP likewise never contained massively labeled elements, except in the stalk in the immediate vicinity of the lesion site (these being retrogradely filled via their axons) or in the immediate vicinity of the injured basal lamina (1 specimen). After incubation with HRP in the incubation medium, the pineal lumen always contained HRP-reaction product. This was never the case after application of HRP to the pineal stalk and was never observed in the specimens analyzed below.
In the pincal stalk, most labcled ncurons were oriented with their long axes more or less radially. Somatal shapes varied from round to elongate (Figs. 1-4). In most neurons, only a thin cytoplasmic sheet surrounded the nucleus, which almost filled the soma (Fig. 1). From the apical pole of the soma, a constricted myoidlike process (Figs. 1-3) extended toward the central lumen of the pineal stalk. The shape of this apical process was varied from cell to cell: In some cases, it was relatively long and thin; in others, it was bulbous (Figs. 1, 2). It often possessed a ciliumlike structure (Fig. 4). Because of the heavy HRP filling of these neurons, the cytoplasm was too dense for ciliary basal rootlets or microtubuli to be discerned.

The apical process, with or without ciliumlike appendages, seemed to lie in contact with widenings of the extracellular space (Fig. 5) which sometimes could be observed to be continuous with the pineal lumen (Fig. 6). It may be assumed that they are generally in contact with the pineal lumen for the following reasons. The pineal epithelium seems to be divided into an apical and a basal portion by a junctional complex, similar to the external junctional complex ("external limiting membrane") of the retina. This junctional complex connects photoreceptor cells and supporting cells, so that the apical portion - in the case of photoreceptors, the inner and outer segments - is in contact with the pineal lumen, while the basal portion - the soma and basal pedicles - is in contact with the perivascular space (Omura et al., 1985). In the present study, the apical processes of the HRP-labeled cells were oriented toward the pineal lumen and were always observed in the vicinity of photoreceptor outer or inner segments, or nearby $9 \times 2+2$ cilia arising from the apical poles of supporting cells.

The apical process invariably contained numerous mitochondria and, in a few cases, synaptic ribbons and presynaptic densities (Fig. 7). Some neurons had an apical process with several thin branches. Such branches were always too thin to contain any mitochondria (Figs. 5, 8). They were never postsynaptic to any receptor or neural structure.

Apical processes, with numerous mitochondria, were in a few cases associated with irregular whorls of membrane lamellae. The cytoplasmic side of these lamellae contained HRP-reaction product.

The basal pole of these labeled neurons gave rise to a process directed more or less toward the peripheral basal lamina of the pineal stalk. This basal process, which could give rise to several shorter branches and evaginations, seemed to represent a small dendrite formation. From its proximal portion, the axon emerged and joined other centrifugally coursing axons, forming part of the pineal tract. The shorter branches and evaginations were the most commonly observed postsynaptic sites for the basal pedicles of the photoreceptor cells (Figs. 9, 10). Photoreceptors were also observed to terminate directly on neural somata, often in association with small cytoplasmic evaginations (Fig. 11).

In the pineal end-vesicle, HRP-labeled elements were essentially similar to those observed in the pineal stalk [except for the large neurons in the rostral "pineal ganglion"-see Ekström and Korf (1985) - which will be analyzed in a following paper].

\footnotetext{
Figure 1, Two HRP-filled neurons in the pineal stalk. Note the long apical process (asterisk) and its myoidlike part ( $M$ ). $N$, nucleus. Scale bar, $1.0 \mu \mathrm{m}$. Figure 2, HRP-filled neuron with a bulbous apical process (asterisk) with a short myoidlike portion (M). Note the basal process (open arrow) from which the axon emerges. $N$, nucleus. Scale bar, $1.0 \mu \mathrm{m}$. Figure 3. HRP-filled neuron with a large apical process (asterisk) filled with mitochondria. $M$, myoidlike structure; $N$, nucleus. Scale bar, $1.0 \mu \mathrm{m}$. Figure 4 , The long and slender apical process (asterisk) of an HRP-filled neuron. Note the ciliumlike structure $(C)$. Scale bar, $1.0 \mu \mathrm{m}$.
} 

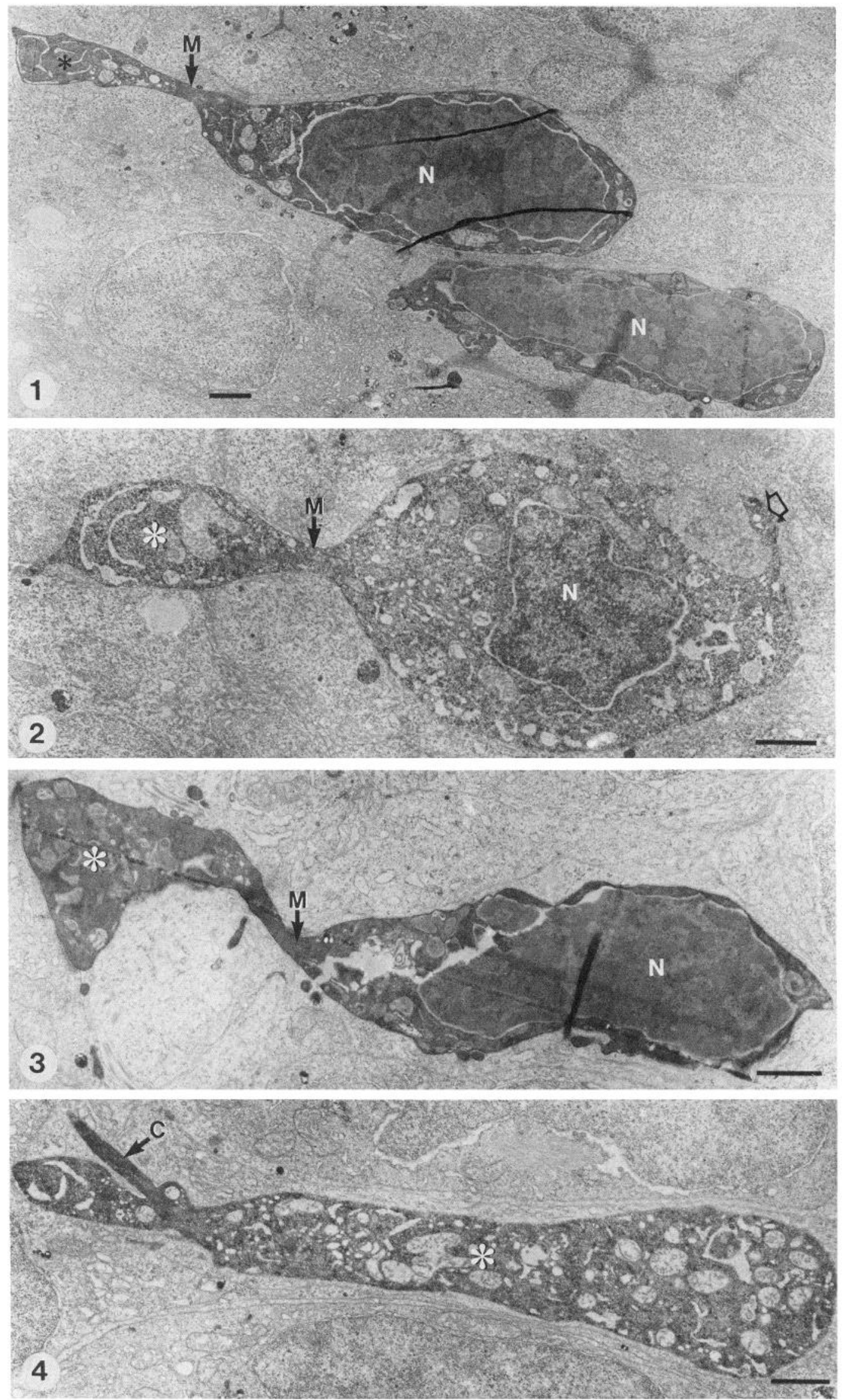

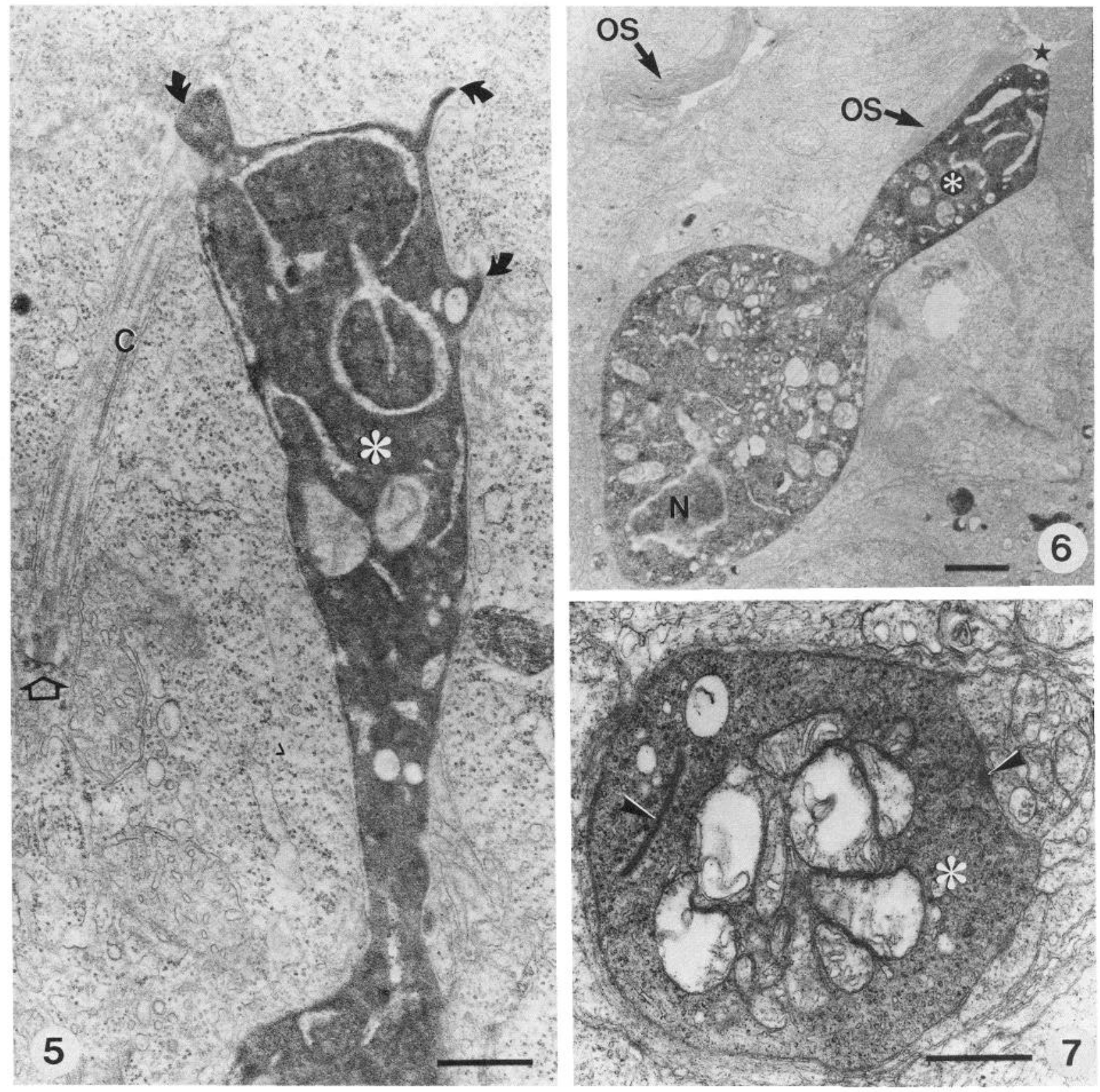

Figure 5, Apical process with microvillous protrusions (curved arrows). Note the cilium $(C)$ with basal rootlet (open arrow) from an unstained cell. Scale bar, $0.5 \mu \mathrm{m}$. Figure 6, Apical process (asterisk) of an HRP-labeled neuron lies in direct contact with the pineal lumen (star). The pineal lumen is an extension of the third ventricle. Note the lamellar stacks of photoreceptor outer segments $(O S)$ near the labeled neuron. Scale bar, 0.5 $\mu \mathrm{m}$. Figure 7, Apical process with a synaptic ribbon (arrowhead) and a possible presynaptic density (arrow). Scale bar, $0.5 \mu \mathrm{m}$.

However, in addition, very large photoreceptor cells were retrogradely labeled with HRP. A photoreceptor soma typically contained a large nucleus and was connected, via a well-developed myoid zone, with a large ellipsoid. Each ellipsoid contained large numbers of mitochondria and gave rise to a modified cilium with membrane lamellae-photoreceptor outer segment-with surrounding microvilli (Figs. 12, 13). Up to 40 lamellae were observed to originate in 1 modified cilium. These photoreceptors were not observed to possess either pre- or postsynaptic specializations adjacent to other photoreceptors or neural elements.

The results are summarized in Figure 14.

\section{Discussion}

The present study challenges prevailing views of the pineal organ on the following points. First, the second-order neurons in the pineal stalk, which receive synaptic input from photoreceptors, are CSF-contacting neurons. This provides us with another type of CSF-contacting neuron (other than the photoreceptors) that may have evolved into the pinealocytes of mammals. Second, CSF-contacting neurons in the pineal organ might indicate the presence of sensory or secretory elements that are postsynaptic to photoreceptor cells. Third, CSF-contacting neurons in the pineal organ may also be presynaptic to other neural elements. 

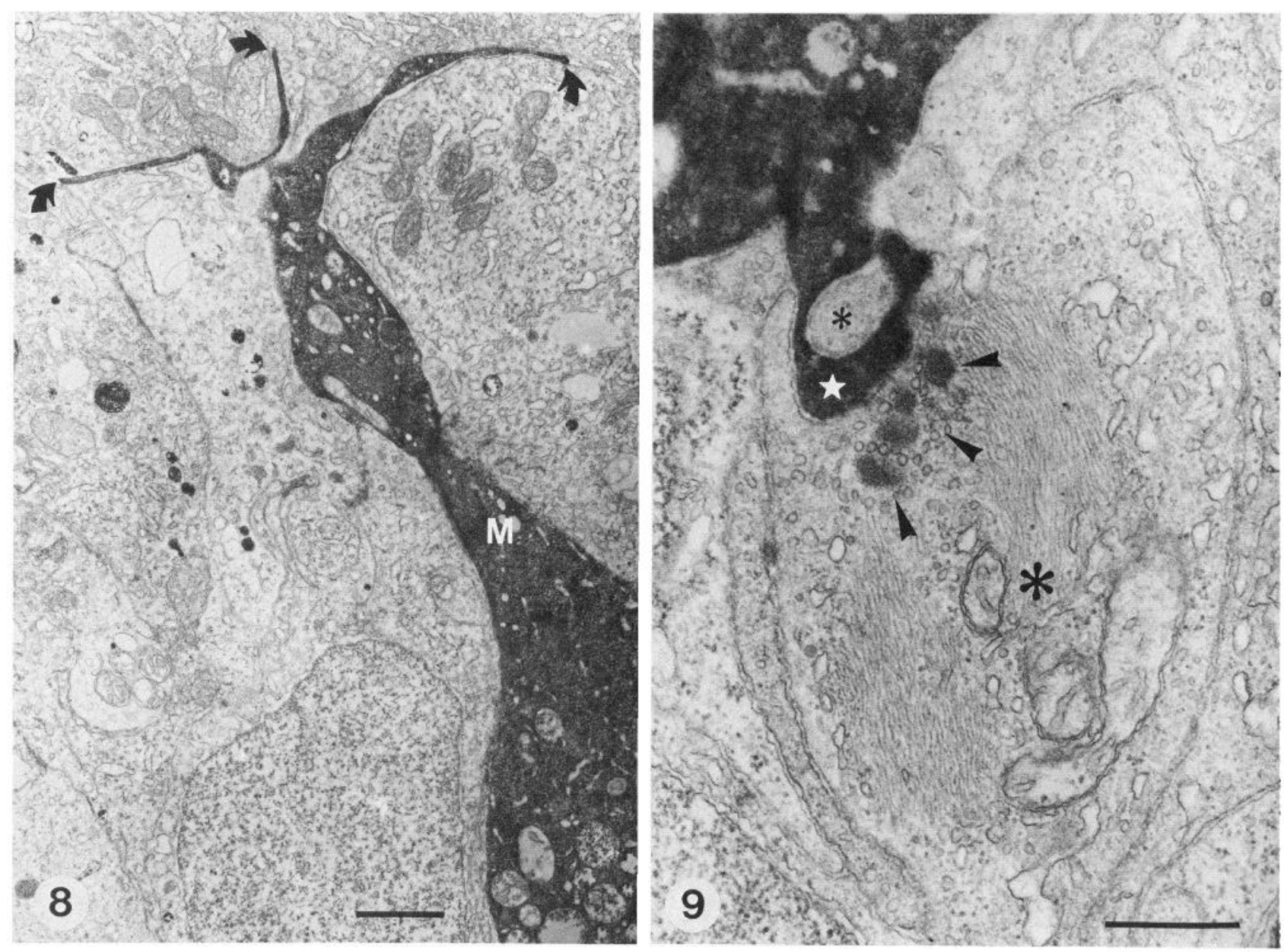

Figure 8, Apical process with thin, filamentous, protrusions (curved arrows). $M$, myoidlike part. Scale bar, $1.0 \mu \mathrm{m}$. Figure 9, Photoreceptor basal pedicle (asterisk) with synaptic ribbons (arrowheads) adjacent to an HRP-filled neuron. Note the interdigitation of the neuronal basal process (star) and the photoreceptor basal pedicle (small asterisk). Scale bar, $0.5 \mu \mathrm{m}$.

Fourth, the presence of CSF-contacting neurons in the pineal stalk that have axonal projections into the brain is not in accord with the view of pinealocytes/photoreceptors as intrapineal CSFcontacting neurons with only local connections. Fifth, the presence of pineal photoreceptors that have long axonal connections indicates the possibility that they may directly influence the activity in various brain centers by means of graded potentials.

The observation that a large proportion of the second-order neurons-in fact, the majority-may be a previously unrecognized type of CSF-contacting neuron prompts the following question: What is the phylogenetic relationship between these CSF-contacting neurons and the pinealocytes of mammals? The concept that the pineal photoreceptors of poikilothermic vertebrates have evolved into secretory pinealocytes that are indirectly influenced by light has been supported by a vast number of comparative histological, histochemical, and ultrastructural studies (reviewed by Collin and Oksche, 1981). Similarly, the concept that pinealocytes (including the photosensory phylogenetic predecessors) are special types of CSF-contacting neurons is supported by numerous comparative studies (reviewed by Vigh-Teichmann and Vigh, 1983, 1985). Accordingly, the typical photoreceptors and all transitory stages toward secretory pinealocytes have received much more attention than other cel- lular elements of the poikilotherm pineal organ. While pinealocytes typically make up for about $80 \%$ of the cellular elements of the mammalian pineal (Vollrath, 1981), photoreceptors constitute a much smaller part of the total cell number in, at least, the pineal organ of the rainbow trout. Thus, the CSF-contacting neurons in the pineal stalk might also be considered forerunners of mammalian pinealocytes. In this context, it is interesting to note the strong similarity between the CSF-contacting neurons with bulbous apical processes and pinealocyte type I cells of Pévet and Collin (1976), which were considered a rudimentary photoreceptor.

Two major objections might be raised. First, it is well established that there are several histochemical similarities between mammalian pinealocytes and pineal photoreceptors of poikilothermic vertebrates. They contain indolamines (review by Møller and van Veen, 1981), and they contain proteins that share immunological properties with the retinal photoreceptor-specific proteins $\alpha$-transducin (van Veen et al., 1986b), S-antigen (Mirshahi et al., 1984; Korf et al., 1986b; van Veen et al., 1986a), and even opsin (Korf et al., 1985). Second, they have been characterized by axonal processes terminating within the pineal organ (Collin and Oksche, 1981). However, we also have indirect evidence that the CSF-contacting neurons in the pineal 

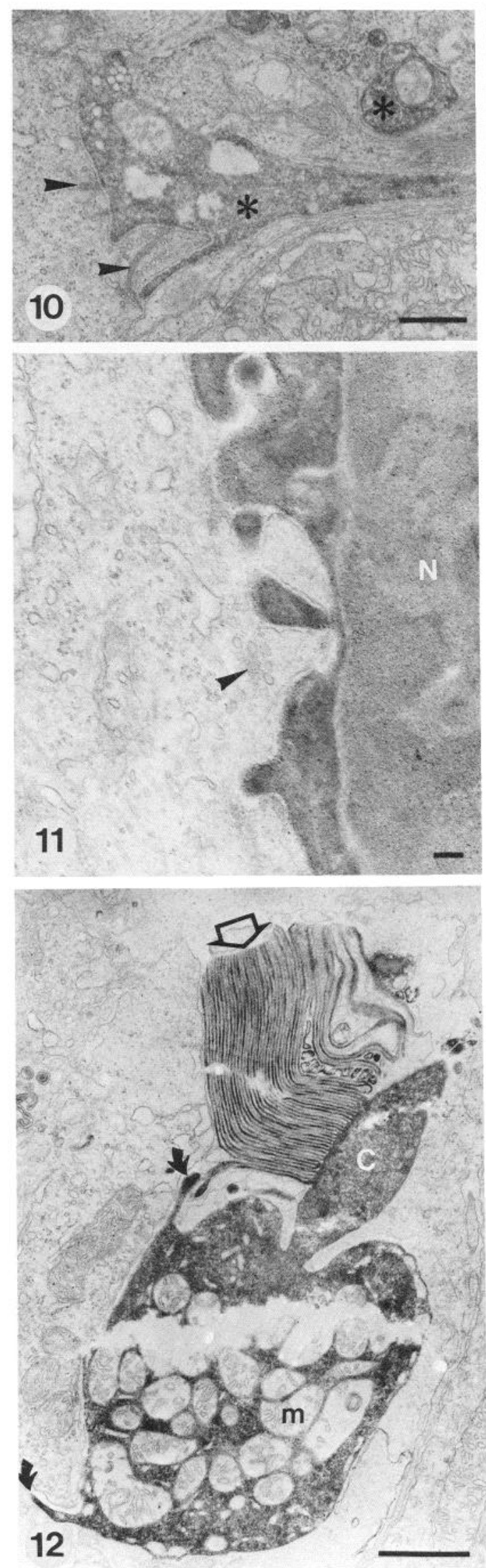

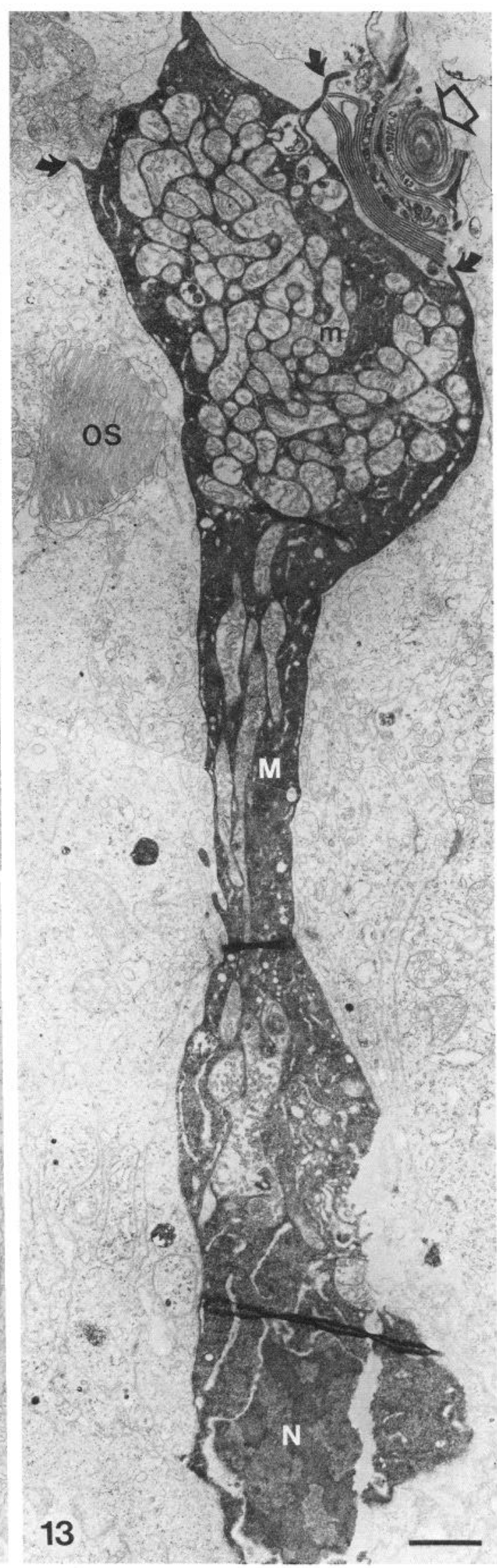




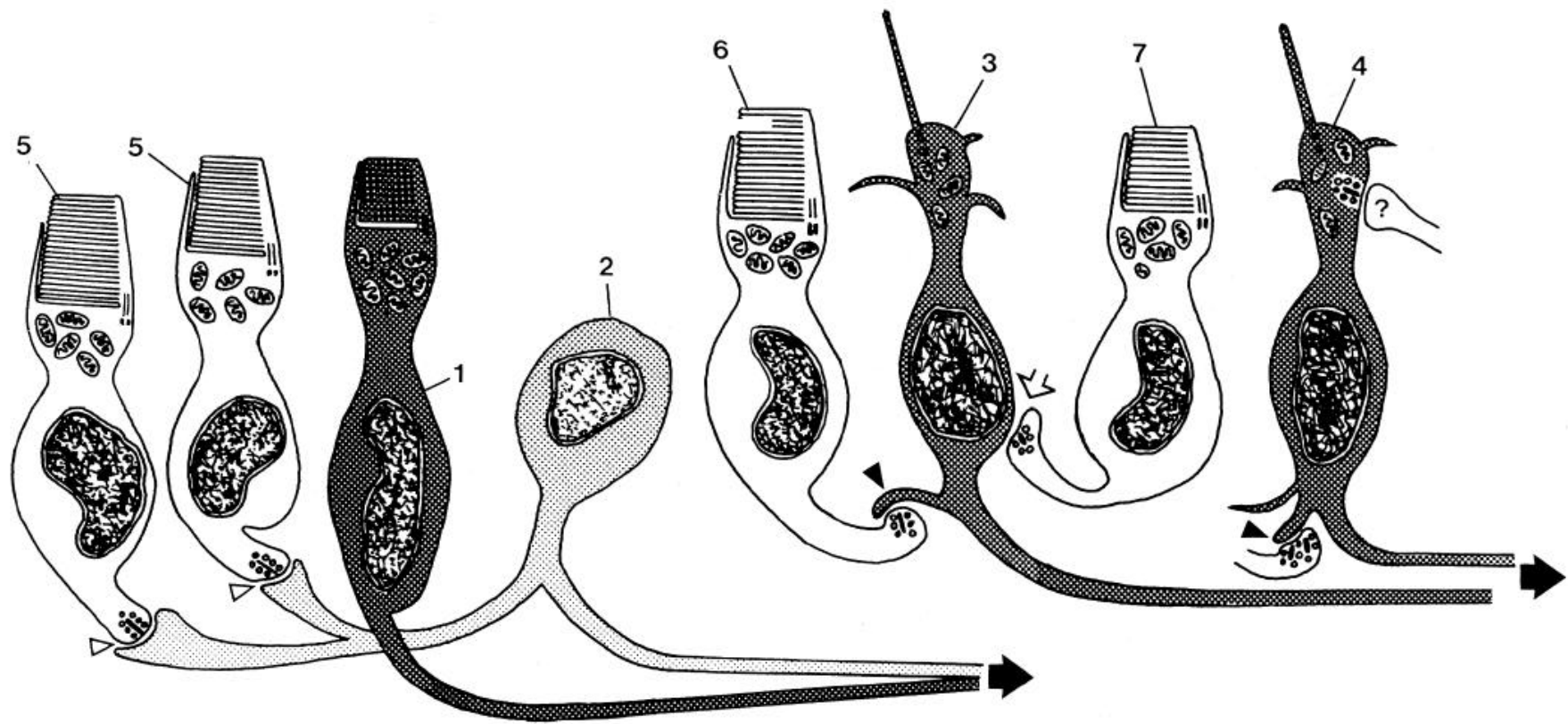

Figure 14. Schematic representation of synaptic connections of neural elements that were retrogradely labeled with HRP (stippled cells). 1, Photoreceptor in the rostral part of the pineal organ, with direct axonal connections with the brain. This type of photoreceptor was not observed to be either pre- or postsynaptic to other neural elements. 2, Neuron in the rostral part of the pineal organ. In this part, an accumulation of projection neurons is found (Ekström and Korf, 1985). The synaptic connections of these neurons are still under study (P. Ekström, unpublished observations), but it, is assumed that they receive mainly direct input from photoreceptor cells (open arrowheads). 3, CSF-contacting neuron in the pineal stalk, receiving axodendritic (arrowhead) or axosomatic (open arrow) inputs from photoreceptor cells. 4, CSF-contacting neuron in the pineal stalk, receiving axodendritic input (arrowhead) from photoreceptor cells. This cell type was sometimes observed to be presynaptic to unknown elements (?). 5, Photoreceptors in the rostral part of the pineal organ, with basal synapses on projection neurons. 6 and 7, Photoreceptors in the pineal stalk, where they may synapse on basal dendrites (6) or on neuronal somata (7). Large arrows denote axonal connections with the brain.

stalk may share histochemical properties with the mammalian pinealocyte, since the majority of the cells in the pineal stalk of the rainbow trout are immunoreactive with antibodies against 5-HT, S-antigen, $\alpha$-transducin, or opsin (P. Ekström, R. G. Foster, H. W. Korf, and J. J. Schalken, unpublished observations). Furthermore, we have recently been able to demonstrate that S-antigen-immunoreactive pinealocytes in the golden hamster pineal organ display axonal processes that can be traced into the habenular nuclei and the dorsal thalamus (Korf et al., 1986a). We observed similar projections of S-antigen-immunoreactive processes from the pineal organ into the habenular nuclei in the rainbow trout, and in a cyprinid fish, Phoxinus phoxinus (P. Ekström, R. G. Foster, H. W. Korf, and J. J. Schalken, unpublished observations).

It has long been a matter of debate whether the dendritelike, ciliated, intraventricular protrusions of CSF-contacting neurons represent sensory or secretory specializations, although most authors favor the sensory functions (Leonhardt, 1980; VighTeichmann and Vigh, 1983). The principal similarity between the CSF-contacting neurons in the pineal stalk and the bipolar cells of the retina that possess a Landolt's club should be stressed. Vigh et al. (1983) were the first to point out the general similarity between these retinal neurons and CSF-contacting neurons. It is possible that Landolt clubs, as well as pineal CSF-contacting neurons, might have a sensory function, analyzing some aspect of the cerebrospinal fluid. The CSF-contacting neurons in the pineal stalk are, as the bipolars of the retina, second-order neurons to photoreceptor cells. We have, unfortunately, no information regarding their mode of signal transmission, whether graded potentials or action potentials.

The presence of synaptic ribbons and presynaptic densities in the apical processes of some CSF-contacting neurons is intriguing. So far, I have been unable to make a conclusive identification of the postsynaptic elements, but these presynaptic specializations could be an indication of feedback mechanisms directly influencing the pineal photoreceptors. Putative feedback synapses onto photoreceptor cells have been described in the trout pineal organ by Omura and Ali (1980).

According to the classical view, the mammalian pinealocyte possesses only short axonlike processes that display terminal formations, either on other pinealocytes (by synaptic ribbon contacts), on the basal lamina of the perivascular space, or in the perivascular space (e.g., Wartenberg, 1968; Vigh et al., 1975). Similarly, the pineal photoreceptor of poikilotherms has been

Figure 10, Photoreceptor basal pedicle with synaptic ribbons (arrowheads) in contact with a neuronal basal process (star). Scale bar, $0.5 \mu \mathrm{m}$. Figure 11, Cross-sectioned synaptic ribbon (arrowhead) adjacent to an HRP-labeled neuronal soma. $N$, nucleus. Scale bar, $0.1 \mu \mathrm{m}$. Figure 12, The ellipsoid of an HRP-filled photoreceptor cell in the rostral part of the pineal organ. A modified cilium $(C)$ gives rise to numerous membrane lamellae, forming the photoreceptor outer segment (open arrow). Note the microvillous protrusions (curved arrows). $m$, Mitochondria. Scale bar, $1.0 \mu \mathrm{m}$. Figure 13, Same HRP-labeled photoreceptor as shown in Figure 12. $M$, myoid region; $m$, mitochondria; $N$, nucleus; curved arrows, microvillous protrusions; open arrow, photoreceptor outer segment. Note that an adjacent photoreceptor $(O S)$ is unstained, showing that the HRPlabeling of certain photoreceptor cells is not due to an unspecific, general, uptake of HRP by the pineal tissue. Scale bar, $1.0 \mu \mathrm{m}$. 
described as possessing short basal pedicles, with terminals either on dendrites of intrapineal neurons (with synaptic ribbons) or in the perivascular space (without synaptic specializations). The former type should then represent the true sensory photoreceptor, and the latter a rudimentary photoreceptor type with indolaminergic and/or peptidergic secretory functions (review in Collin and Oksche, 1981). In all cases, pinealocytes and pineal photoreceptors were regarded as possessing only local, intrapineal, connections. The presence of HRP-labeled, CSF-contacting neurons and photoreceptors with direct axonal projections to the brain indicates the presence of a previously unrecognized cell lineage in the pineal pedigree.

The significance of pineal photoreceptors with long-range projections is enigmatic. Vertebrate photoreceptors are typically endowed with short axons and regulate their synaptic output with graded hyperpolarizing potentials in response to light (Dowling and Dubin, 1984). The signal decrement of thesc graded potentials is no problem, since most photoreceptor axons (i.e., the distance the signal must be propagated) are short, in the range of $10 \mu \mathrm{m}$. Propagation of neural signals by action potentials, which would overcome the difficulties presented by the long distances covered by the pineal photoreceptor axons under consideration, is not known from vertebrate photoreceptors. However, evidence is accumulating that graded potentials are utilized in neural signaling over relatively long distances.

Nondecremental propagation of graded potentials seems to occur over distances of $400-500 \mu \mathrm{m}$ in the thin $(0.5 \mu \mathrm{m} \mathrm{di-}$ ameter), passively conducting axon of goldfish horizontal cells (Weiler and Zettler, 1979; Sakuranaga and Naka, 1985). This is not compatible with cable theory. Rather, Nelson et al. (1975) calculated that this thin interconnecting axon should function as an isolation of the dendritic from the axonal arborizations. Foveal cones in the primate retina have axons up to $600 \mu \mathrm{m}$ long (Polyak, 1941), and amacrine cells may have dendritic arbors where graded potentials convey signals over distances in the millimeter range (Vallerga and Deplano, 1984). Thus, there is no general evidence against the proposal that pineal photoreceptors, which have been retrogradely labeled by HRP via the pineal tract, could be able to transmit photic information to the brain by means of passively conducted graded potentials.

Photoreceptors in invertebrates may possess very long axons (ca. $10-80 \mathrm{~mm}$ ), along which graded potentials are propagated with little, if any, decrement (Shaw, 1972; Hudspeth et al., 1977; Behrens and Fahy, 1981). Similarly, second-order visual interneurons may transmit graded potentials over relatively long distances (Wilson, 1978). These axons are relatively thick, with diameters ranging between 10 and $25 \mu \mathrm{m}$. On the contrary, pineal photoreceptor axons are only ca. $1 \mu \mathrm{m}$ thick, and cable theory would predict that a passively conducted graded potential should attenuate to microvolt levels very rapidly.

However, graded potentials in the micro- and millivolt ranges have been reported to be sufficient to elicit postsynaptic responses (Fain et al., 1977; Stuart and Oertel, 1978). Such small potentials may be discriminated from membrane noise by electrical coupling of photoreceptors (Shaw, 1972; Lamb and Simon, 1976). There are indications that electrical coupling cxists bctween pineal photoreceptors in the rainbow trout. Intracellular injections of Lucifer yellow revealed extensive dye-coupling of pineal photoreceptors (Ekström and Meissl, 1986).

Propagation of graded potentials over long distances could be made possible by a higher specific membrane resistivity in the outer membrane of the axon than in the soma (IIudspeth et al., 1977; Wilson, 1978). Unfortunately, it is not possible to measure the specific membrane resistivity for the ca. 1- $\mu \mathrm{m}$-thick pineal photoreceptor axons. However, assuming membrane resistivities in the range of those calculated by Hudspeth et al. (1977) or Wilson (1978), the attenuation of signals along the pineal tract should not be so great that postsynaptic responses could not still be elicited, at least theoretically.

Before we can speculate about what type of information is conveyed by the directly projecting photoreceptors and CSFcontacting neurons, we need to know their exact axonal termination sites and what type(s) of terminals they make. They may transmit neural signals as retinal photoreceptors, i.e., by release of glutamate or a related substance in the dark (Brandon and Lam, 1983), but they may also act by release of indolamines, neuropeptides, or other substances. Unfortunately, our attempts to identify the ncurotransmittcrs uscd by the centrally projecting elements of the pineal organ have been fruitless (Ekström and Korf, 1986a, b). Identification of the transmitter substances and ultrastructural characterization of the terminal formations of the pinealofugal axons are urgently needed to resolve this issue.

\section{References}

Behrens, M. E., and J. L. Fahy (1981) Slow potentials in non-spiking optic nerve fibers in the peripheral visual system of Limulus. J. Comp. Physiol. 141A: 239-247.

Brandon, C., and D. M. K. Lam (1983) L-Glutamic acid: A neurotransmitter candidate for cone photoreceptors in human and rat retinas. Proc. Natl. Acad. Sci. USA 80:5117-5121.

Collin, J.-P., and A. Oksche (1981) Structural and functional relationships in the nonmammalian pineal gland. In The Pineal Gland, Vol. 1, Anatomy and Biochemistry, R. J. Reiter, ed., pp. 27-68, CRC Press, Boca Raton, Fla.

Dodt, E. (1963) Photosensitivity of the pineal organ in the teleost, Salmo irideus (Gibbons). Experientia 19: 642-643.

Dowling, J. E., and M. W. Dubin (1984) The vertebrate retina. In Handbook of Physiology, The Nervous System III, Part 1, J. M. Brookhart and V. B. Mountcastle, eds., pp. 317-339, American Physiological Society, Bethesda, Md.

Eakin, R. M., and J. A. Westfall (1961) The development of photoreceptors in the Stirnorgan of the treefrog, Hyla regilla. Embryologia 6: 84-98.

Ekström, P. (1984) Central neural connections of the pineal organ and retina in the teleost Gasterosteus aculeatus L. J. Comp. Neurol. 226: 321-335.

Ekström, P. (1985) $\Lambda$ nterograde and retrograde filling of central neuronal systems with horseradish peroxidase under in vitro conditions. J. Neurosci. Methods 15: 21-35.

Ekström, P., and H.-W. Korf (1985) Pineal neurons projecting to the brain of the rainbow trout, Salmo gairdneri Richardson (Teleostei). In vitro retrograde filling with horseradish peroxidase. Cell Tissue Res. 240: 693-700.

Ekström, P., and H.-W. Korf (1986a) Putative cholinergic elements in the photosensory pineal organ and retina of a teleost, Phoxinus phoxinus L. (Cyprinidae). Distribution of choline acetyltransferase immunoreactivity, acetylcholinesterase-positive elements, and pinealofugally projecting neurons. Cell Tissue Res. 246: 321-329.

Ekström, P., and H.-W. Korf (1986b) Substance P-like immunoreactive neurons in the photosensory pineal organ of the rainbow trout, Salmo gairdneri Richardson (Teleostei). Cell Tissue Res. 246: 359 364.

Ekström, P., and H. Meissl (1986) Physiological and morphological characterization of pineal photoreceptors: Intracellular recordings combined with HRP and Lucifer Yellow staining. Pfluegers Arch., Eur. J. Physiol. (Suppl.) 406: R16.

Ekström, P., and Th. van Veen (1984) Pineal neural connections with the brain in two teleosts, the crucian carp and the European eel. J. Pineal Res. 1: 245-261.

Ekström, P., B. Borg, and Th. van Veen (1983) Ontogenetic devel- 
opment of the pineal organ, parapineal organ, and retina of the threespined stickleback, Gasterosteus aculeatus L. (Teleostei). Cell Tissue Res. 233: 593-609.

Fain, G. L., A. M. Granda, and J. H. Maxwell (1977) Voltage signal of photoreceptors at visual threshold. Nature 265: 181-183.

Hudspeth, A. J., M. M. Poo, and A. E. Stuart (1977) Passive signal propagation and membrane properties in median photoreceptors of the giant barnacle. J. Physiol. (Lond.) 272: 25-43.

Korf, H.-W., R. G. Foster, P. Ekström, and J. J. Schalken (1985) Opsin-like immunoreaction in the retinae and pineal organs of four mammalian species. Cell Tissue Res. 242: 645-648.

Korf, H.-W., A. Okschc, P. Ekström, I. Gcry, J. S. Zigler, and D. C. Klein (1986a) Pinealocyte projections into the mammalian brain revealed with S-antigen antiserum. Science 231: 735-737.

Korf, H.-W., A. Oksche, P. Ekström, Th. van Veen, J. S. Zigler, I. Gery, P. Stein, and D. C. Klein (1986b) S-antigen immunocytochemistry. In Pineal and Retinal Relationships, D. C. Klein and P. J. O'Brien, eds., Academic, New York (in press).

Lamb, T. D., and E. J. Simon (1976) The relation between intercellular coupling and electrical noise in turtle photoreceptors. J. Physiol. (Lond.) 263: 257-286.

Leonhardt, H. (1980) Ependym und circumventriculäre Organe. In Handbuch der mikroskopischen Anatomie des Menschen, Vol. 4, A. Oksche and L. Vollrath, eds., pp. 177-666, Springer, Berlin.

Meissl, H., and E. Dodt (1981) Comparative physiology of pineal photorcccptor organs. In The Pineal Organ: Photobiology-Biochronometry-Endocrinology, A. Oksche and P. Pévet, eds., pp. 6180, Elsevier/North-Holland, Amsterdam.

Meissl, H., and P. Ekström (1986) Rod- and cone-like components of pineal photoreceptor responses. Pfluegers Arch., Eur. J. Physiol. (Suppl.) 406: R17.

Mirshahi, M., J.-P. Faure, P. Brisson, J. Falcón, J. Guérlotte, and J.-P. Collin (1984) S-antigen immunoreactivity in retinal rods and cones and pineal photosensitive cells. Biol. Cell 52: 195-198.

Møller, M., and Th. van Veen (1981) Fluorescence histochemistry of the pineal gland. In The Pineal Gland, Vol. 1, Anatomy and Biochemistry, R. J. Reiter, ed., pp. 69-94, CRC Press, Boca Raton, Fla.

Morita, Y. (1966) Entladungsmuster pinealer Neurone der Regenbogenforelle (Salmo irideus) bei Belichtung des Zwischenhirns. Pfluegers Arch. 289: 155-167.

Morita, Y., M. Tabata, and S. Tamotsu (1985) Intracellular responses and input resistance change of pineal photoreceptors and ganglion cells. Neurosci. Res. Suppl. 2: S79-S88.

Nelson R., A. Lützov, H. Kolb, and P. Gouras (1975) Horizontal cells in cat retina with independent dendrite systems. Science 189: 137139.

Oksche, A. (1971) Sensory and glandular elements of the pineal organ. In Ciba Foundation Symposium on the Pineal Gland, G. E. W. Wolstenholme and J. Knight, eds., pp. 127-146, Churchill, London.

Omura, Y., and M. A. Ali (1980) Responses of pineal photoreceptors in the brook and rainbow trout. Cell Tissue Res. 208: 111-122.

Omura, Y., H. W. Korf, and A. Oksche (1985) Vascular permeability (problem of the blood-brain barrier) in the pineal organ of the rainbow trout, Salmo gairdneri. Cell Tissue Res. 239: 599-610.
Pévet, P., and J. P. Collin (1976) Les pinealucyles de Mammifere: Divérsité, homologies, origine. Etude chez la Taupe adulte (Talpa europaea L.). J. Ultrastruct. Res. 57: 22-31.

Polyak, S. L. (1941) The Retina, University of Chicago Press, Chicago.

$\mathrm{Pu}, \mathrm{G}$. A., and J. E. Dowling (1981) Anatomical and physiological characteristics of pineal photoreceptor cell in the larval lamprey, Petromyzon marinus. J. Neurophysiol. 46: 1018-1038.

Sakuranaga, M., and K.-I. Naka (1985) Signal transmission in the catfish retina. I. Transmission in the outer retina. J. Neurophysiol. 53: $373-389$

Shaw, S. R. (1972) Decremental conduction of the visual signal in barnacle lateral eye. J. Physiol. (Lond.) 220: 145-175.

Stuart, A. E., and D. Oertel (1978) Neuronal properties underlying processing of visual information in the barnacle. Nature 275: 287290.

Tabata, M., T. Tamura, and H. Niwa (1975) Origin of the slow potential in the pineal organ of the rainbow trout. Vision Res. 15: 737740 .

Vallerga, S., and S. Deplano (1984) Differentiation, extent and layering of amacrine cell dendrites in the retina of a sparid fish. Proc. R. Soc. London [Biol.] 221: 465-477.

van Veen, Th., R. Elofsson, H. G. Hartwig, I. Gery, M. Mochizuki, V. Cena, and D. C. Klein (1986a) Retinal S-antigen: Immunocytochemical and immunochemical studies on the distribution in animal photoreceptors and pineal organs. Exp. Biol. 45: 15-25.

van Veen, Th., T. Östholm, P. Gierschik, $\Lambda$. Spiegel, R. Somers, H.W. Korf, and D. C. Klein (1986b) $\alpha$-Transducin immunoreactivity in retinae and sensory pineal organs of adult vertebrates. Proc. Natl. Acad. Sci. USA 83: 912-916.

Vigh, B., I. Vigh-Teichmann, and B. Aros (1975) Comparative ultrastructure of cerebrospinal fluid-contacting neurons and pinealocytes. Cell Tissue Res. 158: 409-424.

Vigh, B., I. Vigh-Teichmann, P. Röhlich, and A. Oksche (1983) Cerebrospinal fluid-contacting neurons, sensory pinealocytes and Landolt's clubs of the retina as revealed by means of an electron microscopic immunoreaction against opsin. Cell Tissue Res. 233: 539-548.

Vigh-Teichmann, I., and B. Vigh (1983) The system of cerebrospinal fluid contacting neurons. Arch. Histol. Jpn. 46: 427-468.

Vigh-Teichmann, I., and B. Vigh (1985) CSF-contacting neurons and pinealocytes. In The Pineal Gland. Current State of Pineal Research, B. Mess, Cs. Rúzsás, L. Tima, and P. Pévet, eds., pp. 71-88, Akadémiai Kiadó, Budapest.

Vollrath, L. (1981) The pineal organ. In Handbuch der mikroskopischen Anatomie des Menschen, Vol. 6/7, A. Oksche and L. Vollrath, eds., Springer, Berlin.

Wartenberg, H. (1968) The mammalian pineal organ: Electron microscopic studies on the fine structure of pinealocytes, glial cells and on the perivascular compartment. Z. Zellforsch. 86: 74-97.

Weiler, R., and F. Zettler (1979) The axon-bearing horizontal cells in the teleost retina are functional as well as structural units. Vision Res. 19: 1261-1268.

Wilson, M. (1978) Generation of graded potential signals in the second order cells of locust ocellus. J. Comp. Physiol. 124A: 317-331. 